\title{
Distribution of Diacylglycerylhydroxymethyltrimethyl- $\beta$-alanine (DGTA) and Phosphatidylcholine in Brown Algae
}

\author{
Shigeru Araki ${ }^{1,4}$, Waldemar Eichenberger ${ }^{2}$, Takemaro Sakurai ${ }^{1}$ \\ and Naoki Sato ${ }^{3}$ \\ 1 Yamamoto Nori Research Laboratory, 5-4-6, Oomori-Higashi, Oota, Tokyo, 143 Japan \\ ${ }^{2}$ Institut für Biochemie, Universität Bern, Freiestrasse, 3 CH-3012 Bern, Switzerland \\ ${ }^{3}$ Department of Botany, Faculty of Science, University of Tokyo, Tokyo, 113 Japan
}

\begin{abstract}
Lipids were analyzed in thirteen species of brown algae collected at the seashore near Tokyo, Japan. Diacylglycerylhydroxymethyltrimethyl- $\beta$-alanine (DGTA), a recently identified betaine lipid, was found as a major lipid component in eight species of brown algae examined, namely, Ishige okamurai, Dictyota dichotoma, Pachydictyon coriaceum, Padina arborescens, Hizikia fusiformis, Sargassum horneri, S. ringgoldianum and S. thunbergii. However, phosphatidylcholine (PC) was not detected in any of these algae except 1 . okamurai. By contrast, PC was found as a major lipid component in five other species, namely, Colpomenia sinuosa, Endarachne binghamiae, Scytosiphon lomentarius, Eisenia bicyclis, Undaria pinnatifida. These algae in turn did not contain detectable amounts of DGTA. The fatty acid composition of four selected species, S.lomentarius, U.pinnatifida, D.dichotoma and H.fusiformis, was also studied. The fatty acid components of DGTA in D. dichotoma and $H$. fusiformis were similar to those of PC in U. pinnatifida, the major components being 16:0, 18:2 and 20:4 $\omega 6$ (also 16:1 in D. dichotoma).
\end{abstract}

Key words: Betaine lipid - Brown algae - DGTA - Fatty acid - Phosphatidylcholine.

Brown algae (Phaeophyceae) are an important group in the Chromophyta. They contain Chls $a$ and $c$ as photosynthetic pigments and are yellowish-brown in color (Green et al. 1989). In spite of the fact that some species of brown algae, such as Undaria pinnatifida, Hizikia fusiformis and Laminaria japonica, are important sources of food in Japan, there are few reports on the lipids of the brown algae. Different sulfur-containing lipids from three species of Fucaceae were described by Pham Quang Liem and Laur (1976a, b). Smith and Harwood (1984) analyzed the lipids from Fucus serratus, and they reported an

Abbreviations: MGDG, monogalactosyl diacylglycerol; DGDG, digalactosyl diacylglycerol; SQDG, sulfoquinovosyl diacylglycerol; PC, phosphatidylcholine; PE, phosphatidylethanolamine; PG, phosphatidylglycerol; PI, phosphatidylinositol; PS, phosphatidylserine; DGTS, 1(3),2-diacylglyceryl-3(1)- $0-4^{\prime}$ $(N, N, N$-trimethyl)homoserine; DGTA, 1(3),2-diacylglyceryl-3(1)$O-2$ '-(hydroxymethyl)( $N, N, N$-trimethyl)- $\beta$-alanine; TLC, thinlayer chromatography.

${ }^{4}$ To whom correspondence and requests for reprint should be addressed. unknown Dragendorff-positive lipid which was clearly distinguishable by TLC from PC and DGTS. The same compound was also present in Ascophyllum nodosum (Jones and Harwood 1987). In the course of studies on the lipid composition of three species of brown algae, namely, Hizikia fusiformis, Undaria pinnatifida and Scytosiphon lomentarius, we found that $H$.fusiformis contained an unidentified, Dragendorff-positive lipid which was similar to the unknown lipid detected by Smith and Harwood (1984), while the lipid was not present in U. pinnatifida and $S$. lomentarius (Araki et al. 1989). H. fusiformis contained PC at a level that corresponded to less than $1 \%$ of the total lipids, whereas this lipid was a major component (more than $10 \%$ of the total) in U. pinnatifida and S. lomentarius.

The unknown lipid from $H$. fusiformis appeared to be very similar to DGTA which was isolated originally from Ochromonas danica (Vogel et al. 1990). DGTS, another betaine lipid from $O$.danica, was isolated by Brown and Elovson (1974). DGTS has been found in many species of green algae (Eichenberger 1982, Sato and Furuya 1985), as well as in pteridophytes and bryophytes (Sato and Furuya 
1984a, b). Since DGTA turned out to be identical to the Dragendorff-positive lipid from Fucus and Ascophyllum (Vogel et al. 1990), it seemed very likely that it would also be present in $H$. fusiformis and other brown algae.

In the present report we describe the identification of DGTA and the distribution of DGTA and PC among different species of brown algae.

\section{Materials and Methods}

Plant materials-Fronds of thirteen species of brown algae, namely, Colpomenia sinuosa, Dictyota dichotoma, Eisenia bicyclis, Endarachne binghamiae, Hizikia fusiformis, Ishige okamurai, Pachydictyon coriaceum, Padina arborescens, Sargassum horneri, S. thunbergii, S. ringgoldianum, Scytosiphon lomentarius and Undaria pinnatifida, were collected at Hayama, on the west coast of the Miura Penninsula, near Tokyo, on March 26, 1990.

Male gametophytes of Ectocarpus siliculosus, Laminaria digitata and thalli of Sargassum muticum were obtained from the algal collection at the University of Konstanz, F.R.G. (Prof. D. G. Müller). These algae were used for qualitative analyses only.

Extraction and separation of lipids-Fronds were washed with distilled water, blotted on filter paper, weighed and cut into small pieces. Lipids were extracted from fresh or lyophilized materials with a mixture of chloroform/methanol $(1: 1, \mathrm{v} / \mathrm{v})$ according to the method of Bligh and Dyer (1959), and then lipid were fractionated into individual lipid classes by two-dimensional TLC on precoated silica-gel plates $(20 \mathrm{~cm} \times 20 \mathrm{~cm}$, Merck 5721 and 5715; Merck) using, as solvents for development, a mixture of acetone/benzene/methanol/water $(8: 3: 2: 1, \mathrm{v} / \mathrm{v}$, solvent 1 ) in the first dimension and a mixture of chloroform/acetone/methanol/acetic acid/water $(10: 4: 2: 3$ : $1, v / v$, solvent 2 ) in the second dimension (Sato and Furuya 1984a). As an alternative solvent system, a mixture of chloroform/methanol/water $(65: 25: 4$, v/v, solvent 3 ) in the first dimension and a mixture of chloroform/methanol/isopropylamine/conc $\mathrm{NH}_{3}$ (65:35:0.5: $5, v / v$, solvent 4 ) in the second dimension were used (Eichenberger 1982). The lipids from O.danica (a chrysophyte) and Porphyra yezoensis (a red alga) were used as references. For semi-preparative work, lipids were separated by TLC in solvent 3 . The Dragendorff-positive lipid was eluted from the plates with a mixture of chloroform/methanol $(2: 1, v / v)$ and purified either by TLC in solvent 4 or by HPLC on a Perkin-Elmer Series 10 Liquid Chromatograph equipped with a column $(4 \mathrm{~mm} \times 250 \mathrm{~mm})$ of Nucleosil $10010 \mu \mathrm{m}$ (Knauer, Hamburg, F.R.G.). The solvent was a gradient of acetonitrile that contained 2.5$15 \%$ water during elution for $10 \mathrm{~min}, 15-20 \%$ water for 5 $\mathrm{min}$ and $20 \%$ water for $5 \mathrm{~min}$. The flow rate was $1.5 \mathrm{ml}$ $\mathrm{min}^{-1}$ and peaks were detected with a Perkin-Elmer LC-75 detector at $210 \mathrm{~nm}$. DGTA had a retention time of 14.3 min. IR spectra were measured on a $\mathrm{KBr}$ support in a Perkin-Elmer 782 spectrophotometer.

Analysis of fatty acid composition-Lipids were visualized on TLC plates by spraying with a fluorescent dye, primuline, dissolved in $80 \%$ aqueous acetone. Spots were scraped off and treated with $5 \%$ hydrogen chloride in methanol at $90^{\circ} \mathrm{C}$ for $2 \mathrm{~h}$. The resulting fatty acid methyl esters were analyzed in a gas-liquid chromatograph (GC9A, Shimadzu, Japan) as described earlier (Araki et al. 1986). The amount of each lipid was determined from the amounts of its constituent fatty acids.

\section{Results}

Detection of DGTA from brown algae-Figures 1A and $1 B$ show typical patterns of separation by TLC of total lipids from Hizikia fusiformis (A) and Undaria pinnatifida (B). Spot 7 in Fig. 1A reacted positively to Dragendorff reagent and was neither a phospholipid nor DGTS, as judged from the $R f$ value in the two-dimensional TLC. This lipid was not found in U. pinnatifida (Fig. 1B). The twodimensional TLC using solvents 3 and 4 showed that D. dichotoma, H. fusiformis, I. okamurai, P. arborescens, S. horneri, S. muticum and S. ringgoldianum contained a lipid that migrated to the same position as authentic DGTA from O.danica (not shown).

IR spectra of the lipid from six species of brown algae are shown in Fig. 2. Absorption bands due to $\mathrm{C}=\mathrm{O}$ $\left(1,740 \mathrm{~cm}^{-1}\right), \mathrm{COO}^{-}\left(1,605 \mathrm{~cm}^{-1}\right), \mathrm{C}-\mathrm{O}-\mathrm{C}$ ester $(1,175$ $\left.\mathrm{cm}^{-1}\right), \mathrm{C}-\mathrm{O}-\mathrm{C}$ ether $\left(1,120 \mathrm{~cm}^{-1}\right)$ and $\mathrm{N}^{+}\left(\mathrm{CH}_{3}\right)_{3}(970$ $\mathrm{cm}^{-1}$ ) were characteristic of all the spectra and were completely consistent with those of authentic DGTA from Ochromonas danica (Vogel et al. 1990) and Fucus vesiculosus (not shown). From these findings, we identified the lipid in spot 7 as DGTA.

Lipid composition of brown algae-The composition of the lipids in thirteen species of brown algae is presented in Table 1. DGTA was detected in eight species, namely, D. dichotoma, H. fusiformis, I. okamurai, P. arborescens, P. coriaceum, S. horneri, S. thunbergii and S. ringgoldianum. It is noteworthy that no PC was found in these species of algae, with the exception of I. okamurai and $S$. thunbergii which contained small amount of PC. In addition, PE was not found in P.coriaceum and D. dichotoma. By contrast, large amounts of PC were detected in C. sinuosa, E. binghamie, E. bicyclis, S. lomentarius and $U$. pinnatifida, whereas DGTA was not found in these species of algae. I. okamurai was the only brown alga analyzed that contained DGTA as well as PC and PE in considerable amounts. From the data obtained by TLC, S. muticum appeared to be another species of Sargassum that contained DGTA but not PC, and DGTA was absent from E. siliculosus and $L$. digitata. However, 

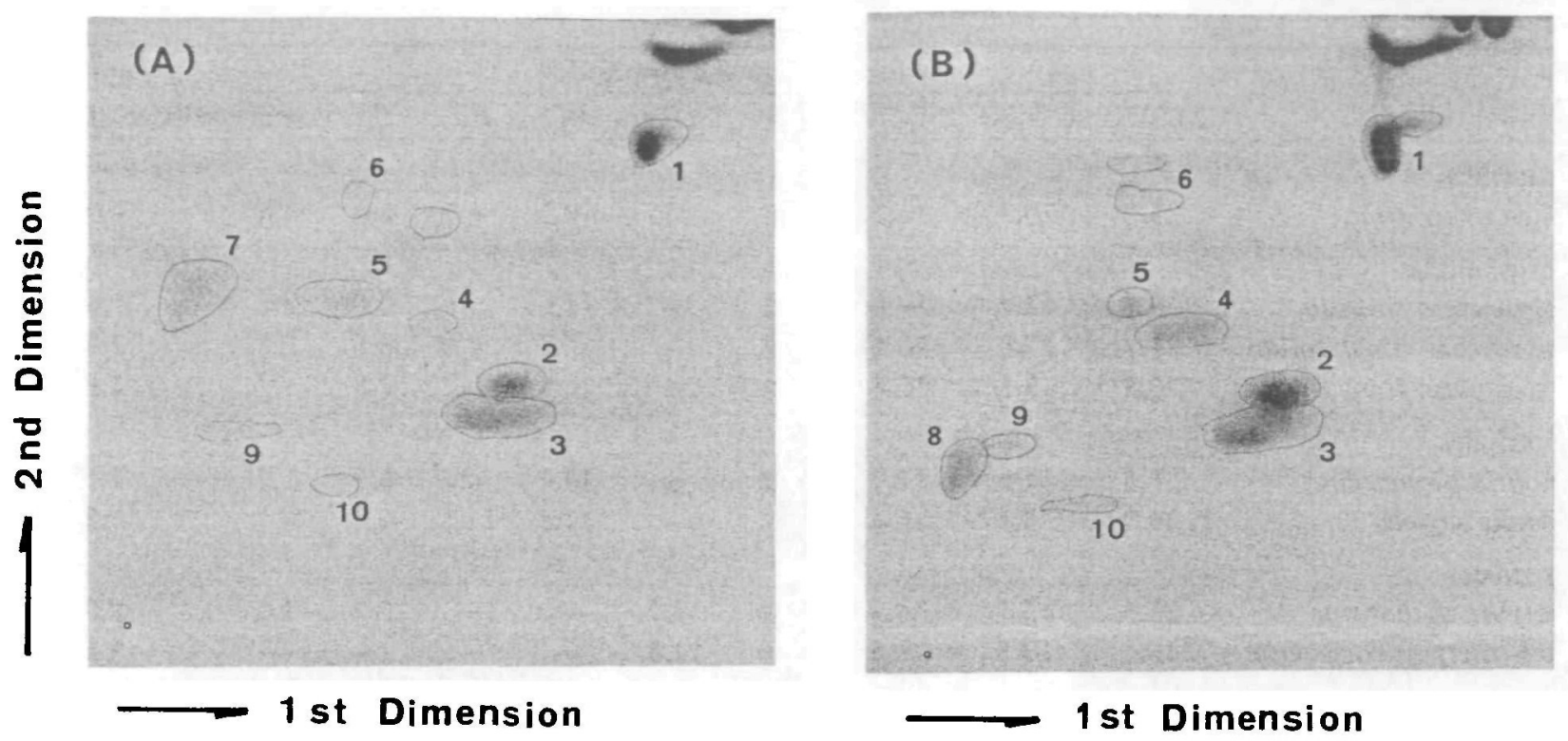

Fig. 1 Thin-layer chromatograms of total lipids extracted from two different species of brown algae. A, Hizikia fusiformis; B, Undaria pinnatifida. 1, MGDG; 2, DGDG; 3, SQDG; 4, PG; 5, PE; 6, unknown (probably PA); 7, DGTA; 8, PC; 9, PS; 10, PI. Solvents: 1st dimension, acetone/benzene/methanol/water ( $8: 3: 2: 1$, by vol); 2 nd dimension, chloroform $/$ acetone $/ \mathrm{methanol} / \mathrm{acetic}$ acid/water $(10: 4: 2: 3: 1$ by vol).

both these latter species contained PC and PE (data not shown).

MGDG, DGDG, SQDG and PC (or DGTA) were the

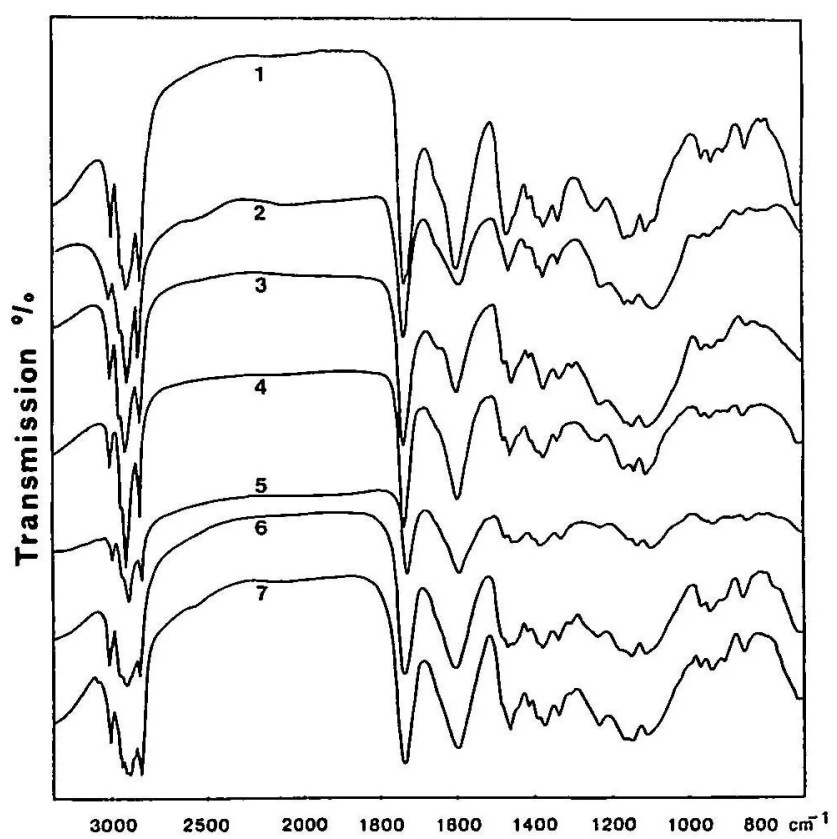

Fig. 2 IR spectra of DGTA from different species of brown algae. $\quad 1$, Ochromonas danica (standard); 2, Ishige okamurai; 3, Dictyota dichotoma; 4, Padina arborescens; 5, Sargassum horneri; 6, S. ringgoldianum; 7, Hizikia fusiformis. major components of the lipids from most of the species of brown algae examined, while PG, PE, PI, PS were minor components. However, E. bicyclis and U. pinnatifida contained PG and PE at a higher level that corresponded to about $10 \%$ of the total.

Fatty acid composition of brown algae-The composition of fatty acids was analyzed in two species of brown algae that contained DGTA, namely, H. fusiformis and D. dichotoma (Table 2) and in two other species that lacked DGTA, namely, U. pinnatifida and S. lomentarius (Table 3).

In $H$. fusiformis and D. dichotoma, the major components of fatty acids in DGTA were $16: 0$ and 20:4 66 (also 16:1 in $D$. dichotoma). This composition is quite different from the fatty acid composition of DGTA from Ochromonas (Vogel et al. 1990), in which 18:0, 20:4 and 22:5 were the major acids. In PC of S. lomentarius and

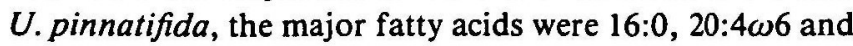
$20: 5 \omega 3$. The fatty acid composition of PE was rather similar to those of PC and DGTA, but the level of 16:0 in PE was lower than that in PC or DGTA.

18:4 and 20:5 $\omega 3$ were the major fatty acid components of MGDG and DGDG from each of the four species of brown algae analyzed, although some differences in the levels of individual fatty acids were noted. 16:0, 18:1 and 18:3 $\omega 3$ were the major components of SQDG, while 16:0, 16:1t, 18:1 and 18:3 $\omega 3$ were abundant in PG. It was also noted that $D$. dichotoma contained a significant amount of 16:1 in most of the lipid classes. 
Table 1 Lipid composition of different species of brown algae

\begin{tabular}{|c|c|c|c|c|c|c|c|c|c|c|}
\hline \multirow{2}{*}{$\begin{array}{l}\text { Order } \\
\text { Species } \\
\end{array}$} & \multicolumn{9}{|c|}{ Lipid composition (mol\%) } & \multirow{2}{*}{$\begin{array}{c}\text { Total lipids }{ }^{a} \\
\left(\mathrm{mg}(\mathrm{g} \text { fr wt })^{-1}\right)\end{array}$} \\
\hline & MGDG & DGDG & SQDG & $\mathrm{PG}$ & DGTA & $\mathrm{PC}$ & $\mathrm{PE}$ & PI & PS & \\
\hline \multicolumn{11}{|l|}{ Chordariales } \\
\hline Ishige okamurai & 23.8 & 20.3 & 14.2 & 4.7 & 5.6 & 18.2 & 6.7 & 2.2 & 4.4 & 4.70 \\
\hline \multicolumn{11}{|l|}{ Scytosiphonales } \\
\hline Colpomenia sinuosa & 26.1 & 12.7 & 19.5 & 7.2 & - & 17.6 & 5.5 & 3.5 & 2.8 & 1.30 \\
\hline Endarachne binghamiae & 25.1 & 13.8 & 20.6 & 7.8 & - & 16.6 & 4.0 & 3.6 & 2.5 & 2.60 \\
\hline Scytosiphon lomentarius & 26.8 & 15.1 & 15.8 & 7.4 & - & 16.8 & 8.2 & 3.8 & 3.2 & 3.90 \\
\hline \multicolumn{11}{|l|}{ Laminariales } \\
\hline Undaria pinnatifida & 31.5 & 14.6 & 17.7 & 14.2 & - & 10.1 & 4.7 & 3.9 & 3.2 & 1.50 \\
\hline Eisenia bicyclis & 26.3 & 3.7 & 16.4 & 13.4 & - & 11.5 & 11.8 & 6.4 & 4.7 & 1.30 \\
\hline \multicolumn{11}{|l|}{ Dictyotales } \\
\hline Dictyota dichotoma & 32.5 & 15.1 & 24.3 & 2.6 & 19.7 & - & - & 0.7 & 1.2 & 2.70 \\
\hline Pachydictyon coriaceum & 46.1 & 10.3 & 21.5 & 3.0 & 14.8 & - & - & - & - & 3.30 \\
\hline Padina arborescens & 39.5 & 8.7 & 21.3 & 3.6 & 10.9 & - & 1.3 & 2.5 & 0.9 & 2.00 \\
\hline \multicolumn{11}{|l|}{ Fucales } \\
\hline Hizikia fusiformis & 27.7 & 9.2 & 29.5 & 5.3 & 15.2 & - & 4.3 & 1.8 & 6.4 & 1.00 \\
\hline Sargassum horneri & 44.1 & 14.9 & 18.0 & 1.6 & 14.1 & - & 1.9 & 1.2 & 1.0 & 2.60 \\
\hline S. ringgoldianum & 46.5 & 10.4 & 18.9 & 3.8 & 12.6 & - & 3.0 & 0.5 & 0.8 & 2.10 \\
\hline S. thunbergii & 28.1 & 11.3 & 23.4 & 7.6 & 20.5 & 1.3 & 2.3 & 1.2 & 1.7 & 3.50 \\
\hline
\end{tabular}

a Total fatty acids.

-: not detected.

\section{Discussion}

Occurrence of DGTA in brown algae-DGTA, a recently discovered betaine lipid, was detected in the nine species of brown algae analyzed in the present study.
Based on these results, a clear relationship is apparent between the distribution of DGTA and the systematics of brown algae. P.coriaceum, D. dichotoma and P.arborescens belong to the order Dictyotales while $H$. fusiformis, S. horneri, S. muticum, S. ringgoldianum and

Table 2 Fatty acid composition of Dictyota dichotoma and Hizikia fusiformis, two DGTA-containing species

\begin{tabular}{|c|c|c|c|c|c|c|c|c|c|c|c|c|c|c|}
\hline \multirow{3}{*}{$\begin{array}{l}\text { Fatty } \\
\text { acids }\end{array}$} & \multicolumn{14}{|c|}{ Fatty acid composition (mol\%) } \\
\hline & \multicolumn{7}{|c|}{ Dictyota dichotoma } & \multicolumn{7}{|c|}{ Hizikia fusiformis } \\
\hline & MGDG & DGDG & SQDG & PG & DGTA & PC & $\mathrm{PE}$ & MGDG & DGDG & SQDG & PG & DGTA & PC & $\mathrm{PE}$ \\
\hline $14: 0$ & 4 & 3 & 11 & 0 & 12 & - & - & 2 & 0 & 2 & 0 & 6 & - & 0 \\
\hline $16: 0$ & 4 & 14 & 38 & 14 & 11 & - & - & 11 & 7 & 51 & 12 & 26 & - & 4 \\
\hline $16: 1$ & 10 & 8 & 11 & 0 & 12 & - & - & 1 & 0 & $\operatorname{tr}$ & 0 & 2 & - & 0 \\
\hline $16: 1 t$ & 0 & 0 & 0 & 39 & 0 & - & - & 0 & 0 & 0 & 37 & 0 & - & 0 \\
\hline 18:1 & 6 & 3 & 17 & 9 & 7 & - & - & 5 & 0 & 12 & 5 & 3 & - & 3 \\
\hline $18: 2$ & 1 & 1 & 2 & 0 & 8 & - & - & 6 & 0 & 3 & 4 & 7 & - & 1 \\
\hline $18: 3 \omega 6$ & 1 & 0 & 0 & 0 & 0 & - & - & 1 & 0 & 0 & 0 & 0 & - & 0 \\
\hline $18: 3 \omega 3$ & 3 & 4 & 10 & 3 & 2 & - & - & 17 & 11 & 11 & 38 & 3 & - & 0 \\
\hline $18: 4$ & 62 & 33 & 2 & 0 & 0 & - & - & 32 & 34 & 1 & 0 & 0 & - & 0 \\
\hline $20: 4 \omega 6$ & 2 & 7 & 3 & 9 & 37 & - & - & 3 & 4 & 1 & 2 & 37 & - & 64 \\
\hline $20: 4 \omega 3$ & 0 & 0 & 0 & 12 & 1 & - & 一 & 0 & 0 & 0 & 0 & 0 & - & 0 \\
\hline $20: 5 \omega 3$ & 6 & 27 & 2 & 5 & 4 & - & - & 19 & 36 & 3 & $\operatorname{tr}$ & 8 & - & 15 \\
\hline Others & 1 & 0 & 4 & 9 & 6 & - & - & 3 & 8 & 16 & 2 & 8 & - & 13 \\
\hline
\end{tabular}


Table 3 Fatty acid composition of Scytosiphon lomentarius and Undaria pinnatifida, two PC-containing species

\begin{tabular}{|c|c|c|c|c|c|c|c|c|c|c|c|c|c|c|}
\hline \multirow{3}{*}{$\begin{array}{l}\text { Fatty } \\
\text { acids }\end{array}$} & \multicolumn{14}{|c|}{ Fatty acid composition (mol\%) } \\
\hline & \multicolumn{7}{|c|}{ Scytosiphon lomentarius } & \multicolumn{7}{|c|}{ Undaria pinnatifida } \\
\hline & MGDG & DGDG & SQDG & PG & DGTA & PC & PE & MGDG & DGDG & SQDG & PG & DGTA & PC & $\mathrm{PE}$ \\
\hline $14: 0$ & 3 & 2 & 6 & 0 & - & 9 & 2 & 1 & 0 & 8 & 0 & - & 4 & 1 \\
\hline $16: 0$ & 5 & 4 & 36 & 21 & - & 18 & 9 & 5 & 5 & 40 & 27 & - & 28 & 15 \\
\hline $16: 1$ & 1 & 1 & 0 & 2 & - & 0 & 0 & 1 & 0 & 0 & 0 & - & 0 & 0 \\
\hline $16: 1 t$ & 0 & 0 & 0 & 19 & - & 0 & 0 & 0 & 0 & 0 & 15 & - & 0 & 0 \\
\hline $18: 1$ & 4 & 3 & 22 & 20 & - & 5 & 3 & 3 & 3 & 16 & 16 & - & 5 & 5 \\
\hline $18: 2$ & 5 & 3 & 7 & 10 & - & 9 & 1 & 3 & 2 & 7 & 9 & - & 10 & 3 \\
\hline $18: 3 \omega 6$ & 2 & 1 & 1 & 0 & - & 0 & 0 & 4 & 1 & 0 & 0 & - & 0 & 0 \\
\hline $18: 3 \omega 3$ & 8 & 6 & 13 & 23 & - & 2 & 0 & 6 & 4 & 15 & 29 & - & 2 & 3 \\
\hline $18: 4$ & 41 & 36 & 7 & 1 & - & 0 & 0 & 55 & 38 & 7 & 0 & - & 0 & 0 \\
\hline $20: 4 \omega 6$ & 2 & 1 & $\operatorname{tr}$ & 1 & - & 19 & 45 & 6 & 11 & 1 & 3 & - & 32 & 50 \\
\hline $20: 4 \omega 3$ & 0 & 0 & 0 & 0 & - & 2 & 0 & 0 & 0 & 0 & 0 & - & 2 & 0 \\
\hline $20: 5 \omega 3$ & 24 & 43 & 7 & 2 & - & 31 & 34 & 13 & 31 & 4 & 0 & - & 4 & 6 \\
\hline Others & 5 & 0 & 1 & 1 & - & 5 & 6 & 3 & 5 & 2 & 1 & - & 13 & 17 \\
\hline
\end{tabular}

S. thunbergii are included in the order Fucales. In Fucus vesiculosus, $F$. serratus and $A$. nodosum, all of which are members of the same order, the presence of DGTA has already been demonstrated (Jones and Harwood 1987, Vogel et al. 1990). Ishige okamurai, the only representative species analyzed from the order Chordariales, also contains DGTA. Thus, it appears, so far, that the distribution of DGTA among brown algae is limited to certain orders, examples of which are the orders, Dictyotales, Fucales and Chordariales. In contrast, members of the order Ectocarpales, Scytosiphonales and Laminariales do not contain DGTA. Obviously, more work is necessary to establish the phylogenetic distribution of DGTA among the brown algae, which comprise 15 different orders (Henry 1984, Wynne 1982). It should be emphasized that DGTS, the other known betaine lipid, which is typical of many green algae, pteridophytes and bryophytes, has not been found in brown algae so far.

In seven of nine species of brown algae, PC seems to be replaced by DGTA. This situation contrasts clearly with the lipid composition of many green algae, in which PC is largely replaced by DGTS, another betaine lipid (Eichenberger 1982, Sato and Furuya 1985). It is still premature to make generalizations about the distribution of DGTA in Chromophyta, the group of algae that contain Chls. $a$ and $c$. O. danica is the organism in which DGTA was discovered (Vogel et al. 1990). A raphidophyte, Chattonella antiqua (Sato et al. 1988) contained DGTS but no DGTA, whereas a marine diatom, Phaeodactylum tricornutum (Arao et al. 1987) contained neither DGTS nor DGTA.

Fatty acid composition of individual lipid classesThe fatty acid patterns of DGTA in D.dichotoma and
$H$. fusiformis were similar to that of $\mathrm{PC}$ in U. pinnatifida.

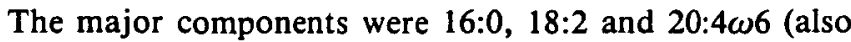
16:1 in D. dichotoma).

The fatty acid composition of individual lipid classes of these species of brown algae, except for D. dichotoma, were essentially similar to that of $F$. serratus (Smith and Harwood 1984), although the contents of C20 polyunsaturated acids in SQDG and PG were somewhat higher in F.serratus. The major fatty acids in glycolipids (MGDG and DGDG) are mainly $\mathrm{C} 18$ and $\mathrm{C} 20$ polyunsaturated fatty acids, whereas the phospholipids (PC, PE) and DGTA mainly contained polyunsaturated C20 fatty acids. Such was the case in $F$. serratus (Smith and Harwood 1984) and in the raphidophycean alga, C. antiqua (Sato et al. 1988). The fatty acid pattern of a marine diatom, P. tricornutum (Arao et al. 1987) was, however, quite different in that it contained high levels of 20:5 103 in all the lipid classes.

Giroud and Eichenberger (1989) reported that DGTS from Chlamydomonas, in which no PC was found, might be actively involved in the metabolism of lipids. This betaine lipid is suggested to act as a primary acceptor of exogenous fatty acids and as a substrate of fatty acid desaturases in Chlamydomonas (Giroud and Eichenberger 1989), as well as in O.danica and Acetabularia (Eichenberger, unpublished results). Although DGTS was not found in brown algae examined, the fact that DGTA was found primarily in the species that do not contain PC suggests that DGTA might play a specific role in the synthesis of lipids in brown algae. This assumption is strongly supported by the rapid labelling of DGTA on incubation of $F$. serratus and $A$. nodosum with $\left[{ }^{14} C\right]$ acetate (Smith and Harwood 1984, Jones and Harwood 1987). 
The authors wish to thank Prof. D. G. Müller, University of Konstanz, F.R.G., for samples of Ectocarpus, Laminaria and Sargassum, and for helpful discussions. The work was supported by Grant 3.061-0.87 from the Swiss National Science Foundation.

\section{References}

Araki, S., Sakurai, T., Omata, T. Kawaguchi A. and Murata, N. (1986) Lipid and fatty acid composition in the red alga Porphyra yezoensis. Jap. J. Phycol. 34: 94-100.

Araki, S., Sakurai, T., Oohusa, T. and Kayama, M. (1989) Distribution of phosphatidylcholine in brown algae. Nippon Suisan Gakkaishi 55: 2049.

Arao, T., Kawaguchi, A. and Yamada, M. (1987) Positional distribution of fatty acids in lipids of the marine diatom Phaeodactylum tricornutum. Phytochemistry 26: 2573-2576.

Bligh, E. G. and Dyer, W. J. (1959) A rapid method of total lipid extraction and purification. Can. J. Biochem. Physiol. 37: 911-917.

Brown, A. E. and Elovson, J. (1974) Isolation and characterization of a novel lipid, 1(3),2-diacylglyceryl-(3)-O-4'-(N,N,N-trimethyl) homoserine, from Ochromonas danica. Biochemistry 13: 3476-3482.

Eichenberger, W. (1982) Distribution of diacylglyceryl-O-4'$(N, N, N$-trimethyl) homoserine in different algae. Plant Sci. Lett. 24: 91-95.

Giroud, C. and Eichenberger, W. (1989) Lipids of Chlamydomonas reinhardtii. Incorporation of $\left[{ }^{14} \mathrm{C}\right]$-acetate, $\left[{ }^{14} \mathrm{C}\right]$-palmitate, and $\left[{ }^{14} \mathrm{C}\right]$-oleate into different lipids and evidence for lipid-linked desaturation of fatty acids. Plant Cell Physiol. 30: 121-128.

Green, J. C., Leadbeater, B. S. C. and Diver, W. L. (1989) The Chromophyte Algae, Problems and Perspectives. Clarendon Press, Oxford.

Henry, E. C. (1984) Syringodermatales ord. nov. and Syringoder- ma floridana sp. nov. (Phaeophyceae). Phycologia 23: 419426

Jones, A. L. and Harwood, J. L. (1987) Comparative aspects of lipid metabolism in marine algae. Biochem. Soc. Trans. 15: 482-483.

Pham Quang Liem and Laur, M.-H. (1976a) Structure, teneurs et compositions des esters sulfuriques, sulfoniques, phosphoriques des glycosyldiglycérides de trois fucacées. Biochimie 58: $1367-1380$.

Pham Quang Liem and Laur, M.-H. (1976b) Les alcohols aliphatiques sulfatés: nouveaux lipides polaires isolés de diverses fucacées. Biochimie 58: 1381-1396.

Sato, N. and Furuya, M. (1984a) Distribution of diacylglyceryl trimethylhomoserine in selected species of vascular plants. Phytochemistry 23: 1625-1627.

Sato, N. and Furuya, M. (1984b) The composition of lipids and fatty acids determined at various stages of haploid and diploid generations in the fern Adiantum capillus-veneris. Physiol. Plant. 62: 139-147.

Sato, N. and Furuya, M. (1985) Distribution of diacylglyceryltrimethylhomoserine and phosphatidylcholine in non-vascular green plants. Plant Sci. 38: 81-85.

Sato, N., Nemoto, Y. and Furuya, M. (1988) Lipids of Chattonella antiqua (Raphidophyceae). Plant Physiol. Biochem. 26: 93-98.

Smith, K. L. and Harwood, J. L. (1984) Lipids and lipid metabolism in the brown alga, Fucus serratus. Phytochemistry 23: 2469-2473.

Vogel, G., Woznica, M., Gfeller, H., Muller, C., Stapfli, A. A., Jenny, T. A. and Eichenberger, W. (1990) 1(3),2-Diacylglyceryl-3(1)-O-2'-(hydroxymethyl)( $N, N, N$-trimethyl)- $\beta$-alanine (DGTA): a novel betaine lipid from Ochromonas danica (Chrysophyceae). Chem. Phys. Lipids 52: 99-109.

Wynne, M. J. (1982) Phaeophyceae. In Synopsis and Classification of Living Organisms. Vol. 1. Edited by Parker, S. P. pp. 115-125. McGraw-Hill Book Co., New York.

(Received December 14, 1990; Accepted April 10, 1991) 